\title{
FORMAÇÃO DISCURSIVA, AUTORIA, FILIAÇÕES E METÁFORA
}

\author{
FORMACIÓN DISCURSIVA, AUTORÍA, FILIACIONES Y METÁFORA
}

\author{
DISCURSIVE FORMATION, AUTHORSHIP, AFFILIATIONS AND METAPHOR
}

\author{
Maria Marta Furlanetto* \\ Universidade do Sul de Santa Catarina
}

"Para Carlos Franchi, por não ter feito escola."

(Dedicatória de Sírio Possenti na abertura de Os limites do discurso)

\begin{abstract}
RESUMO: Neste ensaio, retomam-se as noções de formação discursiva (FD) - a ser questionada -, memória discursiva, identidade e metáfora, estabelecendo um contexto para tratar do processo de autoria. Procura-se argumentar no sentido de que, para além da ressignificação semântica da FD, seria relevante desestruturá-la, como unidade tópica que é, em proveito de redes de discurso (filiações), associadas a territórios fragmentados cuja conformação só teria visibilidade após o percurso analítico. O atravessamento de territórios permitiria fornecer uma imagem (trajeto histórico) teoricamente mais conveniente de um objeto discursivo, visualizando de modo alternativo sua "passagem" na paisagem discursiva, e a heterogeneidade que o caracteriza. Discute-se, ainda, a proposta de FD como unidade não-tópica (conforme postula Maingueneau). A função autoral é retomada nessa configuração, apontando-se possibilidades de análise, incluindo o efeito metafórico.
\end{abstract}

PALAVRAS-CHAVE: Análise de Discurso; autoria; formação discursiva; metáfora.

RESUMEN: En este ensayo, se vuelven a tomar las nociones de formación discursiva (FD) - a ser cuestionada -, memoria discursiva, identidad y metáfora, estableciendo un contexto para tratar el proceso de autoría. Se busca argumentar que, más allá de la resignificación semántica de la FD, sería importante desestructurarla, en su calidad de unidad tópica, en provecho de redes de discurso (filiaciones), asociadas a territorios fragmentados en los que la conformación solamente tendría visibilidad después de ser analizado. Atravesar territorios permitiría proveer una imagen (paso histórico) teóricamente más conveniente de un objeto discursivo, visualizando de manera alternativa su "pasaje” en el paisaje del discurso y la heterogeneidad que lo caracteriza. Además, se discute la propuesta de la FD como unidad non-tópica (postulada por Maingueneau). Se vuelve a tomar la función autoral en esta configuración, señalándose las posibilidades del análisis, incluyendo el efecto metafórico.

PALABRAS CLAVE: Análisis del Discurso; autoría; formación discursiva; metáfora.

ABSTRACT: In this essay we resume the notions of discursive formation (DF) - to be questioned -, discursive memory, identity, and metaphor, establishing a context to deal with the authorship process. We try to reason in a sense that, beyond DF's semantic ressignification, it would be relevant to disrupt it as the topic unit it is, in favor of discourse networks (affiliations) as sociated to fragmented territories with conformation visible only after the analytical course. The crossing of territories would provide a theoretically more convenient image (historical path) of a discursive object, alternativelly aiming its "passage" in the dircoursive landscape, and the heterogeneity that characterizes it. We also discuss the DF's proposal as a non-topic unit (as per Maingueneau). The authorial function is taken up in this configuration, pointing out some analysis possibilities, including the metaphorical effect.

KEYWORDS: Discourse Analysis; authorship; discursive formation; metaphor.

\section{INTRODUÇÃO}

Neste ensaio, interessa-me, especialmente, o processo de autoria, a que associo, como fundamento para o percurso a fazer, reflexões sobre a noção de formação discursiva (FD), memória discursiva, identidade e metáfora no campo da Análise de Discurso de filiação francesa (AD). Ponho em questionamento, contudo, a noção já controvertida de FD, e procuro argumentar no sentido de que, como fez Pêcheux em seu último trabalho publicado ( $O$ discurso: estrutura ou acontecimento?), seria conveniente abandonar o conceito (ainda que reformulado) em proveito de redes, trajetos, temas. Considero, então, uma formação de linguagem plena de efeitos de transversalidade, como um tecido de muitos matizes e muitos tipos de fios. Alternativamente (embora ainda apareça a cicatriz que a expressão reflete pela memória evocada), penso a "formação discursiva"

\footnotetext{
*Programa de Pós-graduação em Ciências da Linguagem - Universidade do Sul de Santa Catarina. Doutora em Linguística Aplicada pela Universidade de Paris VIII - Vincennes. E-mail: maria.furlaneto@unisul.br.
} 
como o faz Maingueneau (2008a): uma unidade não-tópica1 - contrariamente à proposta de "unidade tópica estrutural" tal como se manifestou em parte da pesquisa de Pêcheux, que, em suas últimas reflexões, parece ter-se convencido de que a memória histórica dessa noção perturbava os ajustes na última fase da teoria. Por último, proponho, para averiguação de sua coerência teórica, revestir a noção, tal como explicitada em Maingueneau, com a nomeação "redes discursivas", desmanchando a perspectiva de "identidade” tópica para tratar o processo autoral.

Pode parecer óbvio que noção de FD não deva ser abandonada, apenas ajustada - talvez porque seja uma dessas noções emblemáticas que, uma vez canceladas, poderiam arriscar a sobrevida de uma teoria. Entretanto, não se trata apenas de uma alteração superficial, mas das implicações teóricas do conceito, que não são poucas.

Os fios discursivos que estou manejando trazem uma questão prévia, como se fora um prólogo. Diz respeito ao próprio nome da disciplina (se assim pode ser chamada). Ela brota como efeito de ilusão: por que fazemos Análise de Discurso e não Estudos do Discurso? Ou Análise e síntese de discurso?

O termo, como observa Maingueneau (2012), tornou-se de senso comum, e é lido e usado com efeito de transparência em AD. Tem, poderíamos dizer, uma cicatriz estruturalista à qual não damos atenção. Desde a virada em direção ao estudo do discurso como novo campo de pesquisa, particularmente com o lançamento da revista Langages 13 em número especial de 1969, o termo 'análise’, explica Maingueneau, aparecia de modo ambíguo: a denominação tem origem em Zellig Harris, que, no entanto, realizava uma análise estruturalista do discurso - este tomado como conjunto de unidades de tamanho superior à frase -; e o tema da revista, por sua vez, era apenas um rótulo cômodo para abrigar os textos ali reunidos.

A pesquisa de Pêcheux, na ocasião, tematizava o estruturalismo e a psicanálise. Maingueneau o vê como um "psicanalista do discurso", decompondo textos em frases e submetendo o material a um programa de computador, para agrupá-las em domínios e em paráfrases que poderiam revelar processos ideológicos do texto. E aí 'análise' fazia plenamente sentido. A influência de Foucault ( A arqueologia do saber) sobre a AD foi indireta, mas note-se que a recorrência de "acontecimento" como uma singularidade e a ideia de explicar por que surge como tal mostra que, ao final de seu percurso, Pêcheux retornou a Foucault. E mesmo usando 'análise', em Foucault nada havia que supusesse a decomposição linguística, processo típico da abordagem estrutural.

Pode-se admitir que o rótulo "Estudos de discurso" presuma uma variedade razoável de disciplinas interessadas no discurso, e mesmo “discurso” não está atrelado a uma comunidade homogênea - não há identidade homogênea. De todo modo, analistas de/do discurso, em geral, têm interesses específicos, mesmo sem incluir aí os historiadores do discurso. Todos perseguem uma identidade. Pêcheux, desde o surgimento da AD, fez pesquisas do ponto de vista "parafilosófico" - segundo o termo de Maingueneau: mesmo quando fazia análise automática do discurso, ele tinha como objetivo "[ [...] intervir politicamente num debate epistemológico sobre os fundamentos das ciências sociais.” (MAINGUENEAU, 2012, p. 5, tradução minha), com a pretensão de fundar uma teoria do discurso voltada para a produção de efeitos de sentido, às margens das ciências sociais e da psicanálise, recusando fechar-se num campo já constituído. Convém especificar que esse tipo de abordagem, que era a de Pêcheux, não é a única incorporada pelos analistas; um segundo tipo agrupa aqueles que usam a análise de discurso como "método qualitativo", uma ferramenta das ciências humanas e sociais. Nesse caso, trata-se de haver-se com corpora e sua interpretação num espaço disciplinar específico, mas fugindo ao "risco" de fazer análise de conteúdo - vista como uma metodologia de análise presa ao texto segundo o paradigma positivista, buscando objetivar e quantificar conteúdos de documentos ${ }^{2}$. $\mathrm{O}$ terceiro tipo de analistas inclui pesquisadores do campo do discurso que buscam manter equilíbrio entre a reflexão no campo de estudos e a compreensão dos fenômenos de ordem social, histórica ou psicológica. Estes estão tipicamente ancorados nas ciências da linguagem.

\footnotetext{
${ }^{1}$ Optei por manter a forma com hífen para melhor caracterizá-la, tal como aparece em Maingueneau, apesar do acordo ortográfico vigente para o português.

${ }^{2}$ Hoje a análise de conteúdo é mais refinada, voltando-se também para aspectos qualitativos do material em questão, tentando ultrapassar uma leitura mais presa à linearidade textual. Está voltada a aspectos comunicacionais, lidando com a significação de mensagens e seus contextos e circulação.
} 


\section{FORMAÇÃO DISCURSIVA? VOLTANDO A MAINGUENEAU}

Como observa Maingueneau, podemos nos dar conta de que haverá “[ $[.$.$] apagamento progressivo de uma$ noção vaga que pertenceria a uma época passada", ou mostrar "[...] que a marginalização da noção de formação discursiva testemunha um desvio da análise do discurso.” (2008a, p. 11). Porém, o autor prefere propor uma terceira via: mostrar o interesse e igualmente os limites da noção, refletindo sobre a natureza das unidades em uso pelos analistas de discurso, e, por extensão, sobre a natureza do campo da AD.

É a partir daí que surge a distinção entre unidades tópicas e unidades não-tópicas. Maingueneau chega a esse ponto depois de repassar a "dupla paternidade" da noção (Foucault/Pêcheux), apontando as diferenças e inconsistências subsequentes no uso da expressão. Para ele, "[...] na maioria das vezes emprega-se 'formação discursiva' nas situações em que o analista depara um conjunto de textos que não corresponde a uma categorização clara." (2008a, p. 15). De fato, nunca se sabe o que uma FD comporta, sabe-se apenas que ela, depois de algum tempo circulando, foi observada como "porosa", sendo atravessada por elementos de outras FDs, igualmente porosas. Porém, o que, nesse terreno, identifica uma FD permitindo que ela seja tomada como "unidade" de análise, ainda que não se veja nada de essencial nessa determinação?

Então, para buscar um estatuto para a noção, Maingueneau propõe levar em conta "[ [...] o conjunto de termos que designam as categorias sobre os [as] quais a análise do discurso trabalha." (2008a, p. 16) $)^{3}$. Sinteticamente, ele chega ao que segue:

a) Unidades tópicas são unidades territoriais, remetendo a repartições espaciais com estatuto já reconhecido socialmente (isso pode significar identidade provisória). Aí estão englobados os tipos de discurso remetendo a setores de atividade: discurso administrativo, publicitário, jornalístico... Seriam o que Bakhtin reconhece como esferas sociais, ou ainda entidades como "campo discursivo" e "locutor" (*MAINGUENEAU, 2012, p. 6). Tipos, por sua vez, compreendem gêneros discursivos (dispositivos de comunicação/interação) - também unidades com estabilidade provisória, sujeitas a atravessamentos; o mundo só tem comportas aparentes: a vida social, pragmaticamente, não suporta o caos.

b) Unidades não-tópicas não têm fronteiras preestabelecidas; são construídas pelos pesquisadores, em função de seus objetivos. Os enunciados em questão são, nos termos de Maingueneau, "profundamente inscritos na história [...]" (2008a, p. 18). As formações discursivas, então (admitindo o rótulo), seriam unidades tais como "discurso racista", "discurso colonial", "discurso pedagógico", "discurso feminista”. Assim, rastrearíamos esses discursos em qualquer tipo ou gênero em suas variedades (ou seja, em unidades tópicas) - ensaio, notícia, artigo científico, reportagem, conversação, entrevista... em corpus de arquivo institucional ou em corpus experimental construído para fins de pesquisa.

A busca nos tipos, nos gêneros e nos textos para o estudo do racismo, por exemplo, estaria focalizada nas manifestações do que fosse passível de ser considerado "racismo" - mas abrindo o campo para entender seus matizes e efeitos (não se concebe um sentido como original ou essencial, depois sujeito às vicissitudes do tempo ou das sociedades $\left.{ }^{4}\right)$. $\mathrm{O}$ discurso pedagógico, diga-se ainda, não estaria restrito à divisão institucional do ensino: ele prolifera em termos de atitude, de tom, de efeitos de sentido, e por isso, pode-se dizer, está mais afeito ao conceito de ethos (p. ex., AMOSSY, 2005) do que de FD como espaço tópico, preso à ideia de identidade espaçotemporal que o analista escolhe analisar - mesmo reconhecendo atravessamentos nesse espaço. Ou poderia haver mais de um foco, admite Maingueneau: conjuntos diferentes de gêneros, comparação de épocas, de povos... enfim, definição estabelecida pelo analista, a partir de hipóteses de trabalho que lhe dão um rumo metodológico. Uma formação discursiva assim concebida pode ser construída em torno de um núcleo temático: aborto, greve, um acontecimento específico (cf. também MAINGUENEAU, 2012).

O que isso poderia nos dizer?

\footnotetext{
${ }^{3}$ Examine-se também Maingueneau (2008b, p. 86-88).

${ }^{4}$ Há, digamos, um "descentramento" original - melhor, um não centro primordial (relativamente ao Real do mundo); uma estruturalidade tal como Barthes a concebia em 1971, quando escreveu Da obra ao texto: a linguagem é estruturada, mas sem fechamento; a estrutura é paradoxal: "um sistema sem fim nem centro" (2004, p. 69).
} 
1) que esse discurso estabelecido como uma formação discursiva não estaria concretamente disposto num espaço a que uma posição-sujeito ou várias correspondesse (dependendo dos matizes por deslizamento);

2) que "formação", na composição "formação discursiva", teria um caráter dinâmico, como ressalta Maingueneau: foge-se da configuração de espaço formal estruturado (o que Pêcheux criticou em seu próprio uso), como se já estivesse mais ou menos definido - embora se admita que a FD tem porosidade e se reconfigure incessantemente;

3) que não se trataria de o próprio analista, a seu arbítrio, criar uma formação discursiva para, após a coleta de dados, selecionar o que analisar em busca de regularidades já previstas na FD;

4) que discurso, aí, efetivamente se ofereceria como efeito de sentido entre, dependendo das possibilidades de interpretação e compreensão (no sentido da historicidade da língua de que se trata).

O rótulo, contudo, estaria aí sempre a nos lembrar seu momento de nascimento, como a cicatriz de algo que não se conseguiu esquecer.

Um segundo tipo de unidade não-tópica seria, para Maingueneau, o que ele chama percursos - que parecem ter afinidade com o que encontramos em Pêcheux ([1997] 1983), a partir dos historiadores linguistas, como trajetos temáticos ${ }^{5}$. Ao expor e analisar os efeitos do enunciado On a gagné, Pêcheux toma-o como extremamente opaco, e observado

[...] em uma rede de relações associativas implícitas - paráfrases, implicações, comentários, alusões, etc. - isto é, em uma série heterogênea de enunciados, funcionando sob diferentes registros discursivos, e com uma estabilidade lógica variável. (PÊCHEUX, 1997 [1983], p. 23).

E justamente neste ponto ele apõe uma nota, afirmando que a análise de discurso, desenvolvendo-se nessas bases na ocasião (1983), “[...] se dá precisamente como objeto explicitar e descrever montagens, arranjos sócio-históricos de constelações de enunciados." (p. 60, nota 5) - mas sem as implicações da "formação discursiva": embora retocada depois dessa última investida de Pêcheux, tratava-se de uma concepção estrutural da discursividade, cicatriz sócio-histórica de seu nascimento (umbigo estrutural). Redes de memória e trajetos sociais do discurso, efeito de filiações e trabalho subjetivo de deslocamento - é como Pêcheux se expressa então.

A retomada, por Maingueneau, de formação discursiva, com o esgarçamento promovido, se aproxima também dessa segunda unidade não-tópica que lembra o uso de trajetos sociais por Pêcheux. Os percursos remetem a redes de unidades variáveis (lexicais, proposicionais, fragmentos textuais do interdiscurso) que o pesquisador usa para estabelecer trajetos inesperados, o que é possível com o auxílio de programas informatizados para tratar dados em grande quantidade.

a) percursos de tipo formal: um tipo de metáfora, um tipo de derivação sufixal... no contexto de determinado gênero ou tipo discursivo. O risco é estacionar numa análise linguística;

b) percursos com material lexical ou textual: trabalho com fórmulas discursivas, como o fez Krieg-Planque (2010), e sua dispersão pelos discursos. A autora destaca a relevância das fórmulas na estruturação do espaço público e no tratamento de problemas políticos.

Uma observação final de Maingueneau é relevante aqui: é relativamente fácil e tentador restringir-se, na análise, à visão de unidades tópicas, visto que podem mais facilmente ser objetivadas; as unidades não-tópicas privilegiam um processo radical de interpretação. $\mathrm{O}$ autor entende que, se é importante para uma disciplina das ciências humanas debruçar-se sobre unidades tópicas, propondo "cartografias dos usos linguageiros", não pode haver exclusão das unidades não-tópicas (ultrapassando fronteiras estabelecidas), visto que o interdiscurso (categoria fundamental da análise de discurso) trabalha incessantemente nos furos/nos poros dos espaços arranjados topicamente. Diz ele que há um "impossível fechamento que me parece testemunhar a persistência da noção de formação discursiva [...]” (MAINGUENEAU, 2008a, p. 25) - no sentido estabelecido por ele: de desmanchamento de "fronteiras" aparentemente bem estabelecidas (o que não é, também, algo evidente). Se há riscos em trabalhar com unidades não-tópicas, pelo estilhaçamento das

\footnotetext{
${ }^{5}$ Nesse caso, como explica Branca-Rosoff (2008, p. 133), o pesquisador "estabelece seu próprio arquivo a partir de uma diversidade máxima de fontes: a unidade se faz em torno de cadeias de transformação de enunciados." É uma forma específica de compor um corpus de pesquisa.
} 
materialidades linguísticas que a análise de discurso convoca, há que se considerar que "uma infinidade de relações interdiscursivas atravessa as unidades mais tópicas [...]” (MAINGUENEAU, 2008a, p. 25-26).

Dada a urgência que Pêcheux manifestava em seus últimos trabalhos, é admissível o comentário que faz Maingueneau: de que ele (Pêcheux $)^{6}$ tentou preservar o caráter tópico das unidades e simultaneamente sua inconsistência, daí ter insistido na ideia "[...] de deslocamento, de condensação ou a presença escondida e invasiva do interdiscurso no discurso, e uma visão cartográfica em termos de 'posição de classe', de 'formação ideológica'." (MAINGUENEAU, 2008a, p. 26). Nessa direção, poderíamos dizer que a metáfora era o emblema de um incômodo para a formação discursiva - um processo de invasão.

Além do mais, o que vemos no tema da autoria, hoje tão caro aos analistas, senão uma imagem dessa necessidade de se postar nas fronteiras, junto aos estilhaços que devem ser levantados e arranjados para a obtenção, em movimento contrário, de uma unidade de fechamento sempre provisório, capaz de ser interpretada?

Dou mais um passo. Creio ser interessante expor e comentar uma visão de FD que muitos analistas parecem seguir atualmente como uma possibilidade teórica atraente. Ela se coaduna com a perspectiva de Maingueneau? Vejamos.

\section{FORMAÇÃO DISCURSIVA - UMA DEFESA E ALGUNS CONFLITOS}

Embora reconhecendo o embate vivido por Pêcheux ao destacar que a alteridade na identidade discursiva punha em xeque seu conceito de FD, muitos analistas preferem manter essa categoria de análise, admitindo uma reformulação.

Nesse processo, Indursky (2005) dispôs-se a explorar o problema e argumentar, percorrendo a história da noção e destacando a centralidade de outras noções para a discussão: forma-sujeito, posições-sujeito. Ela traz a concepção básica de Pêcheux, em coautoria com Catherine Fuchs, para FD: o discurso não pode dissociarse do ideológico, de modo que as formações ideológicas têm FDs em sua composição, determinando formas de dizer, com posições especificáveis na conjuntura.

A noção é retomada em Semântica e Discurso, obra emblemática de Pêcheux. Nesse caso, Indursky destaca que a FD corresponde a um domínio de saber com seus enunciados (podemos pensar num espaço tópico), e desse lugar ocorre a interpelação e o assujeitamento ideológico, por meio de uma figura que será conhecida como forma-sujeito - um elemento regulador daquele espaço, coexistindo nele interpelação, identificação e produção de sentido. Porém, em outro capítulo dessa obra, descobre-se uma postura diferente em Pêcheux: ele traz "modalidades de tomada de posição", manifestando a possibilidade de não haver correspondência aos ditames da forma-sujeito. Surgem então os processos de: superposição do sujeito à forma-sujeito; contraposição do sujeito à forma-sujeito (contestação, resistência, criando a contradição e as posições-sujeito na mesma FD); e, finalmente, desidentificação do sujeito à forma-sujeito, provocando uma ruptura.

A autora seleciona o segundo processo para continuar a reflexão, dado que aí é que a homogeneidade da FD fica perturbada. É no texto Remontemos de Foucault a Spinoza, de Pêcheux ${ }^{7}$, que se vê o autor retomando a noção de ideologia e afirmando que não é idêntica a si mesma, que se funda na contradição dos próprios termos. Embora a FD reflita essa contradição, Pêcheux não vê, ainda, motivo para dispensá-la: ela é apenas a mesma e dividida - heterogênea.

A partir disso, Indursky formula sua própria reflexão, admitindo que a forma-sujeito também abriga a diferença. O domínio da forma-sujeito (aqui ela retoma Courtine) comporta diferentes posições-sujeito: a FD é realmente heterogênea. Revisitando outro texto de Pêcheux, Só há causa daquilo que falha ou o inverno político francês (inserido em Semântica e Discurso), ela destaca no autor outra retificação de percurso: ele mostra a relação sujeito interpelado e produção de sentido, e a primazia da metáfora nessa produção ("uma palavra por outra", formulação inspirada em Lacan).

Nessa fase, porém - permito-me abrir um comentário -, Pêcheux faz uma autocrítica tão forte que se esperaria dele o abandono da teoria. A tese da forma-sujeito produz, então, em sua reflexão (em 1978), "um estranho

${ }^{6}$ Maingueneau inclui também Foucault nessa perspectiva.

${ }^{7}$ O texto pode ser lido em L'inquiétude du discours, organizado por Denise Maldidier (1990). 
ruído"; ela é “[...] tomada na História como 'processo sem Sujeito nem Fim(s)'.” (PÊECHEUX, 1988, p. 295). Fora um lance forçado apelar para a noção de "desidentificação" em uma FD por meio de uma "pedagogia da ruptura das identificações imaginárias em que o sujeito se encontra” (p. 298-299, grifo do autor), visto que Pêcheux presumia uma exterioridade teoricista dublada de um pedagogismo invertido, como ele explica, admitindo que fazia “[...] o retorno idealista de um primado da teoria sobre a prática." (p. 299). A noção de FD se esvazia, e, diz Guilhaumou (2005, p. 103), desaparece lexicalmente no período 1982-1983, quando se começa a falar em "leitura de arquivo" (noção utilizada pelos historiadores do discurso); conserva-se, contudo, o caráter de materialidade da filiação de FD ao marxismo, bem como as questões de identidade na relação discurso/sociedade. Como a filiação marxista trazia para a FD a prevalência do discurso dominante (como um sistema de representação referencial), ficava difícil explicar qualquer diferença senão com apelo à subversão - daí aquelas categorias que vemos explicitadas como "modalidades de tomada de posição" (PÊCHEUX, [1975] 1988, cap. IV, seção 3). Ademais, se o objeto privilegiado da análise de discurso era o discurso político, era também uma prática política que associava marxismo e movimento operário - era militância. Mas, reflete Courtine (2006 [1986]), houve um refluxo político, uma despolitização do corpo social, e a "esquerda no poder [...] descobre o pragmatismo político." (p. 31). Cabia mudar o rumo.

Maldidier (1993) explica que, aos poucos, uma série de reorientações acaba se fazendo. Em síntese e em contraste:

a) se a $\mathrm{AD}$ dava lugar metodológico à paráfrase e se voltava para a repetição (homogeneidade), agora devia dar primazia ao outro em detrimento do mesmo - alteridade, heterogeneidade;

b) se tinha o interdiscurso como conceito central, precisava trabalhar a relação interdiscurso/intradiscurso;

c) se, voltada à repetição, tinha interesse pela História (com H maiúsculo) e pelas estruturas antes que pelos acontecimentos, devia então afrontar os acasos da história, as histórias singulares, o acontecimento.

A nova $\mathrm{AD}$ - que vai usar os recursos interpretativos internos ao próprio arquivo, ou seja, na materialidade enunciativa (cf. GUILHAUMOU, 2005, p. 103) - é conduzida, então, pelo contraste entre aquilo que Pêcheux chamou "universos discursivos logicamente estabilizados" e "universos discursivos não estabilizados logicamente", pensados e trabalhados no espaço sócio-histórico. A própria noção de "condições de produção" produzia atrito, visto que regulava a relação de determinação do discurso a partir do exterior pensado como ideologia (interpelação), e, portanto, repelia a heterogeneidade. É então que se torna possível pensar em novas formas de compor o corpus, novas hipóteses e "novos trajetos para a descoberta das redes que constituem o enunciado" (MALDIDIER, 1993, p. 8, tradução minha). Como destaca Maldidier, é nessa via que Pêcheux acaba reencontrando Foucault. Trata-se então da tríade língua, história, interdiscurso.

\section{Retorno à argumentação de Indursky.}

A falha no ritual, diz a autora, decorre do encontro do sujeito (do discurso) com a linguagem e a história ${ }^{8}$, e então novos saberes podem penetrar na FD e reconfigurá-la; outra falha pode fragmentar a forma-sujeito, e outra ainda pode instaurar novas posições-sujeito: um além-FD aparece e causa estranhamento. É aí que Indursky detecta o que chama acontecimento enunciativo. Assim, para ela, “[.... trabalhar com uma FD dotada de tais características coloca o analista de discurso face à agitação e tensão dos sentidos de um domínio de saber e seu gesto de individualização de uma FD consiste já em um gesto de interpretação analítica." (2005, paginação irregular). Passa-me um pouco a impressão de uma cidadela invadida por conquistadores indesejados, com os quais se é obrigado a negociar. É, contudo, uma opção de pesquisa, que, em sua perspectiva mais tópica, também permite o foco em como espaços que guardam mais homogeneidade (considerando regras mais exigentes) acabam negociando, no curso do tempo, a incorporação de elementos "de fora" e sua transformação gradativa.

Para finalizar, a autora mantém a noção, apenas reconhecendo que em vez de "fechamento" da FD deva trabalhar com "efeito de fechamento", que julga necessário para fazer a análise, atendendo a um princípio organizador: a ideologia, ela mesma repartida. Ou seja, o analista ainda precisa "[ $[.$.$] traçar os tênues$ contornos da FD com a qual o sujeito do discurso em análise se identifica" (INDURSKY, 2005, paginação irregular) (cf.. tópico sobre identidade adiante).

${ }^{8}$ Mas note-se que só o sujeito pragmático pode ser olhado separadamente da linguagem. 
Contudo, talvez isso contrarie o espírito de retificação de Pêcheux e a mobilização que ele preconizava nos últimos trabalhos. Vejamos, como um adendo: no final de Papel da memória (1999 [1983], p. 56), ele destaca a memória (pensemos a memória associada à FD) como “[...] um espaço móvel de divisões, de disjunções, de deslocamentos e de retomadas, de conflitos de regularização... Um espaço de desdobramentos, réplicas, polêmicas e contradiscursos.”. Ou seja, nada há aí de conteúdo com sentido homogêneo, acumulado como num reservatório. Ocorre-me fazer uma analogia com o que ele mesmo escreveu de Barthes logo acima, no mesmo texto: Barthes era linguista de textos e teórico das imagens; alternativamente, não era nem linguista, nem semiólogo, nem analista, ele era "o esboço contraditório de gestos que tentamos hoje reencontrar [...]” (p. 56). Era esta sua entrada para nos dizer como queria conceber a memória? Que não seria um reservatório, mas um "espaço" muito heterogêneo, todo atravessado por filigranas mudando de aspecto, embora tendendo a regularizar-se (forças sociais de agregação e dispersão)? Ou, passando a Barthes, que lugar lhe daríamos nas repartições sociais de seu tempo? Como pensar aí num "núcleo duro" que eventualmente sofresse o investimento de unidades externas (ou como se quisesse chamar)? Note-se também que Pêcheux não associou a memória à formação discursiva.

Na reflexão de Guilhaumou (2005, p. 104), dada a “[...] deslocalização tendencial do sujeito enunciador”, na formulação de Pêcheux, a noção estrutural de formação discursiva deixou o lugar para a noção de sujeito empírico, nas pesquisas dos historiadores do discurso. E, diz ele, se importa a ancoragem na realidade da língua, na realidade do indivíduo empírico, na conexão empírica entre realidade e discurso, para ele a função da formação discursiva seria lembrar que o discurso procede tanto da particularidade dos falantes como da generalidade da produção comum de linguagem. Para os historiadores do discurso, evitar a taxonomia de discursos de $\mathrm{X}$, Y ou Z amarrados a FDs X, Y, Z deixava-os mais livres para tratar a história das práticas de linguagem.

Assim, 'formação discursiva' ainda faria sentido se retomada em Foucault:

Falar de formação discursiva para dar conta da regularidade de enunciados dispersos e heterogêneos, no sentido de Michel Foucault, significaria então destacar o modo original e não separado da existência do pensamento e do discurso. A formação discursiva seria então o gênero ao qual pertence qualquer sujeito, qualquer objeto e qualquer conceito apto a significar a existência conjunta da realidade do pensamento e do discurso, pelo fato da existência empírica dos fenômenos linguageiros. (GUILHAUMOU, 2005, p. 109, tradução minha)

Nesse caso, porém, parece que estamos distanciados de qualquer caráter estrutural como receptáculo ideológico, ainda que sujeito a poros muito receptivos.

\section{UM FUNDO FILOSÓFICO PARA PENSAR A LINGUAGEM}

Para refletir um pouco sobre formação discursiva ao lado de redes e filiações, e para subsequentemente retomar questões de autoria, trago este recorte que fiz enquanto lia Rorty (2000, p.145, grifos meus), para mostrar o atravessamento discursivo:

Se há algum valor na ideia de que a melhor posição intelectual é equidistante da direita e da esquerda, então estou indo muito bem. Eu sou sempre citado por guerreiros da cultura conservadora como um desses intelectuais relativistas, irracionalistas, desconstrutores, escarnecedores e sarcásticos, cujos escritos estão enfraquecendo a fibra moral da juventude.

O tom do texto - Trotsky e as orquídeas selvagens - é pessoal, autobiográfico ${ }^{9}$. Destaquei algumas palavras aí: valor, equidistante, direita, esquerda, guerreiros, desconstrutores e fibra. A simples leitura do trecho não leva à certeza de que se trate - em nível de classificação mais alto - de um escrito filosófico, ou - em nível mais baixo - de autobiografia, ou ainda conferência autobiográfica. Resta sempre uma dúvida, resultado da sensação de fluidez de contornos. Podemos, contudo, nos perguntar sobre os itens lexicais com algum nível de estranheza, visto que às vezes não é tão difícil decidir se os termos utilizados são convenientes ou vêm de outro lugar, se os leitores têm saberes suficientes sobre os territórios - geográficos, mentais ou saberes enciclopédicos - que se diz comumente serem fundamentais para entrar no emaranhado dos textos.

${ }_{9}^{9}$ Publicado em Nova Iorque, em 1993. O original tem um subtítulo: Wild orchids and Trotsky: Messages from American universities". 
Assim, poderíamos supor que valor, equidistante, direita e esquerda são comuns em Matemática, em Física, em Economia; que guerreiros remete a conflito armado, vida militar/de militância; que desconstrutores remete a construção, edificação de obra arquitetônica; que fibra nos conduz para a cultura agrária (plantas). Estamos no terreno da heterogeneidade, da memória coletiva. Temos o direito de estranhar, por exemplo, o uso de "orquídeas" por Rorty nesse texto, ao lado de Trotsky - um estranho trajeto. Não sabemos de imediato por que elas estão aí, num texto filósofico. Até mesmo nisso, contudo, fica difícil determinar se em todos os casos se trata de metáfora - relembremos "uma palavra por outra", da formulação de Lacan.

Dizer que se trata de metáfora por provir de outro lugar também pode ser temerário - só é "outro lugar" por termos dividido espaços e ideias em fragmentos (necessidade pragmática), sistematizando classificações (efeito do positivismo), porque criamos cabines nas quais cabe isso e não cabe aquilo, dizendo "isso é Física", "isso é Matemática”, "isso é Direito" ${ }^{10}$. Ou ainda: "isso é $1^{a}$ classe”, "isso é classe econômica”. É subjetivo o estranhamento que dá direção ao que buscamos; são valores emergentes da vida social, com seu selo político, ou de acontecimentos que enquadram nossas formas de viver, sentir e valorar.

Por que Rorty está aquie É que ele afirmou, ao tentar mostrar pontos de convergência entre a filosofia analítica inglesa e a filosofia continental: "[...] nunca seremos capazes de pisar do lado de fora da linguagem, nunca seremos capazes de apreender uma realidade que não seja mediada por uma descrição linguística." (2000, p. 57 $)^{11}$. Com isso, ele parafraseia os slogans das duas orientações, respectivamente: "Toda consciência é um fato linguístico"; "tudo é uma construção social” (com Foucault como ponto de partida). E, por que não dizer, acomoda-se a uma interpretação do "Não há metalinguagem" de Lacan. Em função disso, ele conclui (neste ponto da discussão) que "[ [...] nossas práticas linguísticas estão tão entrelaçadas com nossas outras práticas sociais que nossas declarações da natureza, assim como nossas descrições de nós mesmos, serão sempre uma função de nossas necessidades sociais.” (RORTY, 2000, p. 57).

Contrariamente a entender (ao modo essencialista) que a linguagem é uma barreira que impede que se chegue à natureza intrínseca do mundo, entender-se-á, nessa perspectiva: "A linguagem não pode ser incapaz de representação acurada, já que nunca representou coisa alguma." (RORTY, 2000, p. 60) ${ }^{12}$. Nesse contexto, chegar ao conceito de objetivo (que a ciência parece requerer) leva a uma forma alternativa: (ser) objetivo aparece “[...] como uma referência a uma relativa facilidade em obter consenso" (p. 61), não como uma relação inequívoca com aspectos intrínsecos de objetos.

Com referência ao recorte destacado do trabalho de Rorty, quero dizer que não é fácil deslindar a heterogeneidade (que é constitutiva), porque precisamos de uma referência que não seja absoluta, mas apenas perspectivada. Além disso, para falar de metáfora, será preciso estabelecer uma gradação: deslizamento ou deslocamento? Onde? De onde? Quanto? O estranhamento (referente a algo) não é universal. Até se pode admitir que todo sujeito estranha algo ou alguém, mas o que está em questão é como nossa linguagem nos mostra o mundo (precisamos dela para saber algo do mundo), e não a eventual utilidade ou não de estranhar. Caso contrário, não há mais como situar a metáfora. Pêcheux refletiu bastante sobre metáfora, deixando indícios aqui e ali; não estaria ele vinculando essa reflexão ao investimento sobre a "formação discursiva", já detectando aí uma opacidade teórica?

O estranhamento pessoal ou grupal (prenhe de memória) é que faz dizermos: isso é exótico, é feio, é bom, é verdadeiro, é poético; e isso vem de outro lugar (de outra FD, se fosse o caso de utilizar a noção). É metáfora, deslizamento, deslocamento. Não fora isso, por que falaríamos nesses "deslocamentos"?

Tomo 'deslizamento' como alterações ocorrentes dentro do que concebemos como o mesmo espaço (reconhecido como "mesmo", não causado por uma origem); mexidas quase imperceptíveis, deriva lenta; e

\footnotetext{
${ }^{10} \mathrm{O}$ que dizer deste título condensado: Kant e o ornitorrinco (ECO, 1998)? Eco diz que o ornitorrinco, descoberto na Austrália no final dos anos 1700, foi, inicialmente, chamado (era preciso nomeá-lo) watermole, duck-mole, duckbilled, platypus. Os naturalistas ficaram pasmos com a conformação daquele "animal" (um mamífero que põe ovos...). A pergunta interessante aqui é o que Kant teria feito diante de um ornitorrinco, para classificá-lo, para pensálo em termos de juízo (v. ECO, p. 81 et seq.).

${ }^{11} \mathrm{O}$ trecho consta na conferência Um mundo sem substâncias ou essências.

${ }^{12}$ Lembremos que isso coaduna com a perspectiva da AD: “a linguagem [...] não é transparente nem o mundo diretamente apreensível, quando se trata de significação." (ORLANDI, 1996, p. 28). Ainda: "Como a ordem da língua e a ordem do mundo não são coincidentes elas só funcionam pelo imaginário." (p. 30).
} 
tomo 'deslocamento' como alterações resultantes de viagens de longa distância: metáfora "viva”, não experimentada, não "curtida" ou naturalizada"13.

Por comodidade e necessidade na vida social, repartimos nossos assuntos do cotidiano, da vida profissional, da vida política, religiosa etc. Precisamos saber onde buscar os saberes e valores e como dispor deles (v. como funciona uma biblioteca). Também se torna cada vez mais difícil rearranjar esses saberes por rótulos (v. as divisões praticadas numa livraria, para dar um lugar e ordem aos livros). Social e politicamente, essa conjunção e a hierarquia que se estabelece corresponde, digamos, a um processo autoral de administração do caos (ou da heterogeneidade) - nem sempre bem-sucedido, certamente, e exigindo de tempos em tempos um rearranjo.

Dada essa fragmentação (ou o "estar em/ser fragmento") e a dificuldade política de rearranjar rótulos e territórios, sentimos estar perdidos frente a uma tarefa crítica: produzir, autorar (juntar pedaços, ordenar, fazer arte; ler X, Y, Z.... ${ }^{14}$. E um motivo de fundo, ao lado desse fervilhar de territórios movediços, é que se busca um efeito de originalidade sabendo que o mundo é complexo e que, se há interlocutores "parecidos" conosco, vivendo em culturas e comunidades não distantes, na maior parte das vezes há uma distância que assusta - ainda que imaginária, construída por nossos temores. Isso nos remete ao processo de identificação.

\section{UM ESPAÇO PARA A IDENTIDADE?}

Pensar topicamente a FD e o assujeitamento - ainda que com a possibilidade de variar posições por efeito de contradição no próprio funcionamento da ideologia - nos leva justamente a pensar na identidade (o funcionamento parafrástico no interior da FD): com que forma-sujeito nos identificamos, ou não tanto, ou apenas num momento e não em outro?

Estou ciente de que, neste tópico, estou lidando com autores que têm especificidades epistemológicas; eles falam de lugares teóricos distintos. Ao partir do construto teórico da $\mathrm{AD}$, estou remetendo a discussões de outros campos que, no entanto, tratam do mesmo tema e têm preocupações semelhantes às dos analistas de discurso - o que permite comparar e ampliar perspectivas.

Rememoro aqui, sobre o princípio dialógico, que a "revolução bakhtiniana" - como Ponzio (2008) designa o fenômeno - se manifestou mudando o ponto de referência da fenomenologia. Segundo ele, muda "a visão de mundo dominante em nossa cultura" (p. 11). É que se passa do horizonte do "eu" para o horizonte do "outro"; ou seja, fala-se agora da alteridade como contraponto à categoria de identidade, predominante no mundo ocidental, no pensamento e na práxis, produzindo "abstrações concretas" como: Indivíduo, Estado, Nação, Verdade, Justiça, Liberdade. Tais entidades vigoram no sistema global que reproduz a sociedade em termos absolutos. Isso faz lembrar a frustração e as retificações de Pêcheux? Ora, a alteridade permanente não pode produzir algo acabado. O mundo que aparece na linguagem é polifônico. E a linguagem (relembrando) não representa o mundo.

Geraldi (2011, p. 15), tratando de linguagem e identidade, diz: “[...] falar não é representar o mundo, mas construir uma representação do mundo para si e para os outros.". Faz sentido: "A cada vez que usamos uma ou outra expressão, damos a realidade de um modo distinto." (p. 15). Todas as relações interlocutivas promovem modos de compreensão do mundo, alterando passo a passo as identidades. Se, por um lado, herdamos da configuração social formas de ser em cada espaço (compondo, diga-se, regularidades, séries), por outro, as experiências singulares no mundo empírico de cada sujeito também o modificam paulatinamente. "A história do cotidiano, a micro-história vai mostrando como esses deslocamentos, às vezes imperceptíveis, são essenciais." (GERALDI, 2011, p. 16). E há outras formas de identidade, que Geraldi denomina "máscaras", usadas praticamente sem consciência - aquilo que pensamos como valores ideológicos, que funcionam como um horizonte social amplo e atingem as vidas no cotidiano. Ele exemplifica (citando Bauman) com a ideia do novo, a velocidade de sua emergência e seu desaparecimento. Uma máscara é "o embotamento de nossa capacidade de nos surpreendermos." (p. 17). Outra máscara é o investimento em diferenças identificadoras

\footnotetext{
${ }^{13}$ Seria interessante agregar uma consideração sobre "acontecimento”, mas o espaço é restrito e estou tratando do tema em outro ensaio.

${ }^{14}$ Lat. auctor-oris "origem de, causa principal”.
} 
em termos de grupo, de comunidade, para buscar aceitação. É uma forma de ter identidade. E no capitalismo a diferença se tornou um fetiche que proporciona lucros ("Jogue fora tudo o que você conheceu até agora").

Aproveitando a referência a Bauman, proponho breve comentário com respeito a algumas reflexões dele sobre o tema. Na obra Identidade, que corresponde a uma entrevista dada a Benedetto Vecchi, este, na introdução, informa que Bauman, em seu trabalho de sociólogo, “[ [...] procura estabelecer conexões com fenômenos sociais ou manifestações do etos público que parecem muito distantes do objeto inicial da investigação, e tecer comentários sobre eles." (2005, p. 8) - o que me leva a comentar que a teia das filiações é sempre maior do que se pensa. $O$ pensamento tem natureza errante ${ }^{15}$, e isso torna difícil, nesse caso, afirmar que ele (Bauman) se alinha a uma "escola" de pensamento - e não só ele. De saída, é uma demonstração do problema de falar em "identidade".

Bauman vê a questão da identidade como uma obsessão do debate público contemporâneo, que pode ter consequências nefastas; por exemplo, manter o outsider à distância para não perturbar os laços de um mundo familiar. Se a identidade é uma convenção socialmente necessária, é também um perigo: pode levar a fundamentalismos de todo tipo. O tempo todo a identidade é ambígua (quem se identifica com uma FD?). A maioria das pessoas terá dificuldade para resolver as questões da mesmidade - a consistência e continuidade da nossa identidade com o passar do tempo em uma comunidade de ideias e princípios. Isso porque circulamos pelas comunidades, elas se entrelaçam.

As “identidades" flutuam no ar, algumas de nossa própria escolha, mas outras infladas e lançadas pelas pessoas em nossa volta, e é preciso estar em alerta constante para defender as primeiras em relação às últimas. Há uma ampla probabilidade de desentendimento, e o resultado da negociação permanece eternamente pendente. (BAUMAN, 2005, p. 19, grifo do autor)

Assim, identidade não se descobre, ela aparece como algo a ser inventado: "como alvo de um esforço, um 'objetivo'; como uma coisa que ainda se precisa construir a partir do zero ou escolher entre alternativas [....]" (BAUMAN, 2005, p. 21-22). E isso ocorre quando a questão toca de perto: exílio, desterritorialização, mudanças drásticas...

Passando ao plano especificamente brasileiro, diz um historiador que, na formação de nossa identidade nacional, pretendeu-se utilizar a estrutura escolar " [...] para modelar uma pretensa identidade que atendesse a determinadas perspectivas ideológicas e mesmo doutrinárias", mas os resultados foram inexpressivos (TAMBARA, 2011, p. 22). O destaque em sua perspectiva é que o processo histórico contém um elemento dialético que faz inevitável o confronto entre elementos antagônicos respeitando "interesses bem localizados na arena material da sociedade" (p. 22). Todo o desenvolvimento da formação socioeconômica do país tem como único elemento, contraditoriamente, diz ele, a transformação. Ou seja: é impossível "construir processos de dominação hegemônicos" (p. 21). Em suma: "[...] a identidade brasileira está eivada de contradições e que mascaram as apreensões ingênuas que os interesses da classe dominante impingem na cosmovisão dos cidadãos em geral." (TAMBARA, 2011, p. 41). Como percebemos, são sempre conflitos da ordem do imaginário.

Aliás, uma das alterações realizadas no corpo da $\mathrm{AD}$, relativamente à noção de $\mathrm{FD}$, foi justamente, por coerência, preferir a forma 'identificação' (processo) à forma 'identidade'.

Com esse pano de fundo, passo ao tópico que compõe a cena principal.

\section{AUTORAR (A FUNÇÃO-AUTOR)}

A heterogeneidade já presumida (e incorporada por Pêcheux), conforme a explicitação de Authier-Revuz (cf. AUTHIER, 1982) ${ }^{16}$, e depois sistematizada em seu Ces mots qui ne vont pas de soi (1995), em que explora as múltiplas formas de não coincidências do dizer, é reconhecida por nós desde que tenhamos alguma experiência sobre o funcionamento das formas da linguagem (nos gêneros). Precisamos olhá-las, usá-las e, ao mesmo

\footnotetext{
15 "É preciso suportar o que venha a ser pensado", disse Pêcheux (1988, Anexo 3, p. 304).

${ }^{16}$ A autora retoma o tema em seguida em Hétérogénéité(s) énonciative(s) (AUTHIER-REVUZ, 1984), artigo traduzido para o português e publicado nos Cadernos de Estudos Linguísticos n. 19, da Unicamp.
} 
tempo, sentir o eco de suas possibilidades ao investirmos no lugar do outro. É disso que trata de perto Authier-Revuz (2011 [2004]) no artigo Paradas sobre palavras: a língua em prova na enunciação e na escrita - ao qual faço referência por ter previsto falar de certas "paradas" (pelo turbilhão do excesso e pelo buraco que sempre se cava no processo).

É o processo autoral (individual ou não) que, lidando com as redes - o conjunto memorialístico do ponto de vista interdiscursivo, com todos os tipos de linguagem e valores, somado aos arquivos de consulta institucionais -, reúne fragmentos potencialmente suturáveis entre si (ordenação, paragrafação, citação, pontuação... - que exige também seccionamento) para dar efeito de unidade ao conglomerado de expressões, estabelecendo, no ponto de partida, uma inscrição em esfera e gênero para efetuar a textualização. É o paradoxo de uma escritura, de um arranjo de linguagens.

Os fragmentos do quebra-cabeça devem formar primeiramente um rascunho do conjunto, sempre inacabado porque não é um exercício já preparado por outrem. Haverá excesso e haverá falta. E em algum momento sobrevirá uma parada (um stop) - determinada por injunções externas. A heterogeneidade precisa ser "dominada”, e não pode ser apenas constituída por recortes já datados e produzidos para eventual colagem. Este poderia até ser um processo aceitável para iniciantes - pelo menos, é de onde se pode partir para o desenvolvimento da autoria ${ }^{17}$, pelo esforço necessário de busca e reprodução, antes que o iniciante seja inserido propriamente nas diretrizes de produção de autoria, bem como no conhecimento do que seja má conduta ao avançar nesse processo.

Entendo "parada" de duas formas: o stop é o modo extremo (uma parada interna forçada), em que cessa por tempo indeterminado a reflexão metaenunciativa, esse desdobrar-se da linguagem em função da pulsão de escrita: há um silenciamento por travamento - é como estar à beira de um abismo sem poder sequer enxergar o outro. O "chamado" cessa, se perde; os saberes convocados estão em estado de caos, sem nenhuma ligação visível. A segunda forma é a "parada" de que fala Authier-Revuz: é "o acompanhamento metaenunciativo de uma escrita" - ora muito denso, como exemplifica a autora relativamente a escritos teóricos de Barthes e Derrida, em que há palavras ora sustentadas, ora contrariadas, ora questionadas; ora muito raro, como se a escrita trouxesse evidências puras, dispensando retomadas, escorrendo serenamente ${ }^{18}$.

Mostro um exemplo de Barthes (2004, p. 81); é um recorte de Digressões:

“O formalismo em que penso não consiste em 'esquecer', 'negligenciar', 'reduzir' o conteúdo ('o homem’), mas apenas em não parar no limite do conteúdo (fiquemos provisoriamente com esta palavra); [...]”

Sobre Barthes, Authier-Revuz nota: o "[...] acompanhamento cerrado das aspas inscreve na escrita, ao mesmo tempo, uma intolerância subjetiva à influência do repetido e uma exigência ética do discurso e do pensamento relativamente ao que vai de si." (2011, p. 666). Ele também era pródigo no uso de itálico. Diria que era obcecado pela presença e pelos movimentos de leitura de cada potencial leitor, e então seu tom é insinuante e respeitador.

Outro aspecto da parada e do acompanhamento metaenunciativo corresponde ao que Authier-Revuz define como uma não-coincidência no nível da própria linguagem (do discurso): é quando enfrentamos as palavras alheias - palavras de outro registro, de outra época; palavras estrangeiras, palavras de outras teorias; palavras de jargão, gírias... ao lado da valoração, do posicionamento adotado em vista disso. Que isso afete ou não nosso amor-próprio, o aparentemente fora de nosso mundo particular " [...] é o exterior no sujeito, no discurso, como condição constitutiva de existência." (AUTHIER-REVUZ, 1984, p. 99, grifo da autora, tradução minha). O discurso aparece como produto do interdiscurso - mas não só, visto que aí o esquecimento é estrutural, e o saber não se resume nisso.

As possibilidades que a linguagem abre acabam sendo um bem e uma tortura. E podem levar a um mito, ao qual se chega pela queixa de que a linguagem não é perfeita, não se adapta, por mais que haja esforço, àquilo

\footnotetext{
${ }^{17}$ Não vou aqui me ater ao plano pedagógico, pensando o processo autoral como algo passível de ensino, e em que medida isso poderia ocorrer. Já tratei dessa perspectiva em outras ocasiões.

${ }^{18}$ Não se exclui, claro, que essa escrita tenha sofrido uma limpeza, uma espécie de objetificação. Um iniciante, no entanto, está mais propenso a "ir direto ao ponto", apegando-se à ilusória transparência da linguagem.
} 
que talvez pareça mais ou menos evidente como concepção mental, ou considerando a luxúria tão concreta de dados aguardando análise.

Nesse processo, a repetição não deve dominar: a mera aparência de unidade não satisfaz a produção autoral -

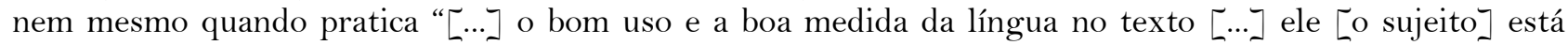
também sujeito à incompletude, à indistinção.” (ORLANDI, 2001, p. 96). Na gradação do processo metafórico reflete-se agora a gradação do processo autoral. Quando ele começa? Como? Até onde pode prosseguir? Há muitas perguntas.

Qual a diferença entre aquilo que vai surgindo como se por conta própria (que vem por si) e a escrita que não consegue evitar dizer de si mesma, deixando pistas metaenunciativas de sua sui-referencialidade ${ }^{19}$ (ou autorreferencialidade)? (cf. BENVENISTE, 1966, p. 274).

Penso que as formas variadas de deixar pistas de gênese na textualização (o embate com a resistência das palavras), independentemente da vontade de trabalhar um estilo, tem a ver com estilo. De todo modo, apoiando Authier-Revuz (2011, p. 673), repito com ela que “o ritmo de uma escrita é uma forma singular da inscrição de um sujeito, com seu corpo, na linguagem e num dizer [...]”, ora sendo escandido serenamente, ora aos solavancos (rasurando, hesitando, comentando), ainda que tendo por objetivo buscar uma unidade limpa e reconhecível, consoante padrões estabelecidos que determinam o reconhecimento de uma comunidade discursiva. Ou seja, buscamos pelo imaginário restaurar essa ilusão de unidade que nos amarra, e simultaneamente reconhecemos que a opacidade não é o lado negativo da linguagem, mas uma de suas faces. É a isso que Authier-Revuz chama, apropriadamente, um “[...] estrato específico da escrita que é a sua música metaenunciativa." (2011, p. 674) ${ }^{20}$.

As ditas não-coincidências do dizer, tais como perspectivadas por Authier-Revuz (1995, 2004), e que levam à tentativa de controle do dizer, são, resumidamente, estas quatro, seguidas de alguns exemplos. Quem produz qualquer dizer precisa negociar com elas.

a) não-coincidência interlocutiva (leva a um ajuste coenunciativo): $\mathrm{X}$, se vocês quiserem; X, como você acaba de dizer. "Se [vocês] nos acompanham, compreenderão, então, que a evidência da leitura subjetiva [...] é uma ilusão constitutiva do efeito-sujeito [...]” (PÊCHEUX; FUCHS, 1990 [1975], p. 169).

b) não-coincidência do discurso com ele mesmo (que leva às figuras de empréstimo): $\mathrm{X}$, para retomar a palavra de...; X, como diria... "Seguramente há inúmeros mecanismos (ou regimes, para usar uma expressão ao gosto foucaultiano) que nos tornam o que somos.” (GERALDI, 2011 , p. 12).

c) não-coincidência entre as palavras e as coisas (com figuras de adequação/inadequação dos nomes): $\mathrm{X}$, é esta a palavra; o que se poderia chamar $\mathrm{X}$; $\mathrm{X}$, ainda que a palavra não seja conveniente. "Tocamos aqui no ponto de vazio (universitário, se ouso dizer) que redobra sua ameaça [...]” (PÊECHEUX, 1981, p. 17).

d) não-coincidência das palavras com elas mesmas (daí as figuras do equívoco, com acolhida ou rejeição): X, mas não no sentido de...; X, em sentido bem estrito. "Experiências extremas (no sentido de opostas)". Título de crônica (NEVES, 2014).

Os indícios que reconheço no processo de autorar parecem dublar a relação língua/história/interdiscurso de modo similar à transfiguração sofrida pela FD, que, ao perder seus contornos tópicos, não pode remeter mais a lugares enunciativos correspondentes a um exterior ideológico dominante. Em 1981 (colóquio Matérialités discursives), Pêcheux passou a destacar, em detrimento do metadiscurso sobre posições enunciativas, o que definiu como "deslocalização tendencial do sujeito enunciador" na materialidade dos textos. Era preciso entregar-se a uma prática que tirasse as consequências dessa deslocalização (PÊCHEUX, 1981, p. 17).

O colóquio, que reunia praticantes de três áreas, trazia, conforme os termos de Pêcheux, suas marcas: “a poeira dos arquivos [historiadores], o giz dos quadros [linguistas] e o suor dos divãs [psicanalistas].”

\footnotetext{
${ }^{19}$ Uso a expressão que Benveniste (1966) aplicou às formas performativas ao analisar a obra de Austin, mas amplio seu escopo.
}

${ }^{20}$ Authier-Revuz também desenvolve este tema em Musiques méta-énonciatives: le dire pris à ses mots (2004), começando por uma resposta ao "Não há metalinguagem” de Lacan, afirmando que sempre pode haver retorno reflexivo do enunciador em direção a suas próprias palavras (produzindo um estrato metaenunciativo) - o que, aliás, como "metaenunciador impenitente" que era, Lacan fazia o tempo todo (cf. p. 85). 
(PÊCHEUX, 1981, p. 15, tradução minha). E era, para os organizadores (entre eles Pêcheux), uma "aposta". Não se esperaria que todos falassem da mesma coisa, mas, tratando-se de materialidades discursivas, a questão era o que resulta como "heterogeneidade irredutível" entre a história, a língua e o inconsciente: “[ …] uma ruminação de palavras ouvidas, relatadas ou transcritas, um formigamento de escritos citando palavras, e outros escritos" (p. 15) - enfim, uma proliferação de material inscrito em todo tipo de gêneros, com rupturas, antagonismos, redes de repetição fazendo fracassar a identidade.

Como fazer análise de discurso nessa conjuntura - tendo como pano de fundo um vazio político? Como ler e como produzir? É aí que ele propõe o que chamou leitura-trituração, leitura que supõe que nos tornemos estrangeiros à própria leitura; que exige "recortar, extrair, deslocar, aproximar". Cabia afastar a análise de discurso dos efeitos de reprodução, fazê-la passar à produção de acontecimentos, a um encontro com o outro, entrando na história, mostrando o que trabalha às margens dos discursos. Iniciar esse trabalho já era, para Pêcheux, "produzir um (pequeno) acontecimento" (1981, p. 18, tradução minha).

E essa memória nos remete ao próprio autorar em geral - que inicia pela leitura-trituração, pelo fazer-se estrangeiro à aproximação de uma "terra" ${ }^{21}$. De alguma forma, isso parece corresponder ao que Sarnel (2007, p. 2) evoca sobre a leitura em Deleuze, alertando ter o filósofo um pensamento ligado à "passagem": há dois modos de ler um livro, um modo clássico e um modo intensivo. No primeiro caso, o livro é como uma caixa onde se vai buscar significados; se isso não funciona, procura-se outro livro; no segundo, tem-se uma leitura relacionada à passagem, ao livro como lugar de passagens, como transversalidade em direção ao exterior; supõe experimentação, eventos para cada um sem vínculo direto com o livro, mas funcionando para outras coisas.

Correlativamente, encontro em Deleuze e Guattari (1995 [1980], p. 18) o que manifesta a escritura, a aventura da autoria pós-leitura em intensidade, em termos de construção de um discurso direto, forjado a partir do primeiro tipo observado por eles, o discurso indireto ${ }^{22}$ :

O discurso direto é um fragmento de massa destacado, e nasce do desmembramento do agenciamento coletivo: mas este é sempre como o rumor onde coloco meu nome próprio, o conjunto das vozes concordantes ou não de onde tiro minha voz. Dependo sempre de um agenciamento de enunciação molecular, que não é dado em minha consciência, assim como não depende apenas de minhas determinações sociais aparentes, e que reúne vários regimes de signos heterogêneos. Glossolalia. Escrever é talvez trazer à luz esse agenciamento do inconsciente, selecionar as vozes sussurrantes, convocar as tribos e os idiomas secretos, de onde extraio algo que denomino Eu [Moi].

Como é perceptível, não se trata de uma tarefa leve, tranquila. Quanto investimento se pode supor ao se encontrar num romance - no caso que exemplifico, policial - o que surge como uma cartilha de busca policial em certo ponto de uma investigação (conselho de um inspetor de polícia a um aluno): "Não pense no que está procurando. Pense naquilo que encontra. Por que está aí? É para estar aí? O que significa? É como ler - se você pensar em um 'l' enquanto olha um 'k', não vai captar as palavras.” (NESBØ, 2009, p. 183).

Escritores formados em leitura de intensidade podem fazer isso com (aparente) espontaneidade: conseguem vincular "paisagens" próximas e longínquas sem perder o efeito de coerência. E nessa ligação comparecem, como cintilações, metáforas, esses efeitos de viagens - ora curtas, ora de grande distância, ora em seu efeito vivo de heterogeneidade, ora em sua arrumação como comparações bem urdidas. Do autor norueguês de romances policiais, citado acima, lemos comparações que soam como a parte divertida em ambiente sombrio de busca policial, tal como: em dia frio e chuvoso, um guarda-chuva revirado pelo vento lembra um morcego espancado. É espantosa a diversidade de campos que é possível aproximar, em formulações bem suturadas. Glossolalia.

\footnotetext{
${ }^{21}$ Ouvi também essa voz em Deleuze e Guattari (1995 [1980], p. 35), ao tratarem de estilo: "Ser um estrangeiro, mas em sua própria língua, e não simplesmente como alguém que fala uma outra língua, diferente da sua.”. Isso tem a ver com a intensividade, jogo com valores e variação.

22 “A 'primeira' linguagem, ou, antes, a primeira determinação que preenche a linguagem, não é o tropo ou a metáfora, é o discurso indireto." (DELEUZE; GUATTARI, 1995 [1980], p. 9, grifo dos autores).
} 


\section{JUNTANDO OS FILAMENTOS}

Neste ensaio, pretendi dar continuidade, a partir de algumas categorias da $\mathrm{AD}$ - com especial atenção à noção controvertida de formação discursiva -, a meu estudo sobre o processo de autoria. Ao pensar em redes, trajetos, temas, desviando a ideia de uma noção aparentemente mais estabilizada, porque tópica, de formação discursiva, fez-se mais adequada a própria compreensão do que sucede no processo de autorar como conjunto de momentos de passagem, como visto aqui com inspiração em Deleuze. Espaços de linguagem, na realização autoral, são plenos de efeitos de transversalidade, de marginalidade, de matizes como em tecido urdido com muitos tipos de fios. Não é, de fato, à toa que falamos em tessitura para a formulação textual, trazendo por imagem um tapete oriental urdido com milhares de nós que produzem o efeito, em superfície, de uma pintura aveludada.

Se a repetição não deve predominar no processo autoral, sabemos que a face mais perceptível da operação é a repetição, a paráfrase (também no que ela tem de deslizamento), a retomada de sentidos, que constituem o estofo, a moldura necessária para a construção da obra. A construção discursiva precisa de uma inscrição em discursos anteriores, associados ou mesmo dispersos, divergentes e distanciados. De fato, contudo, há a retomada não de sentido prêt-à-porter, senão de fragmentos como blocos de construção.

Dessa forma, tendo partido da noção de formação discursiva, cuja versão mais conservadora corresponde a um lugar teórico de localização e tratamento da paráfrase como "matriz" de sentido, com sua forma-sujeito (e a implicação identitária), tentei defender a conveniência de desconstruí-la, retomando a controvérsia, para conduzir a atenção ao nível de produção autoral, compreendendo melhor também os percalços em sua constituição. Essa opção, contudo, não abala o tratamento analítico de unidades tópicas em seu sentido genérico.

Com isso, finalmente, quero significar também que a compreensão paulatinamente mais apurada do processo autoral leva a uma outra face da questão: como trabalhar com autoria desde o ensino fundamental - e todas as questões que a partir daí se desdobram.

A leitura é uma viagem de ida; a escrit(ur)a é a de retorno.

\section{REFERÊNCIAS}

AMOSSY, R. (Org.). Imagens de si no discurso: a construção do ethos. São Paulo: Contexto, 2005.

AUTHIER, J. Hétérogénéité montrée et hétérogénéité constitutive: éléments pour une approche de l'autre dans le discours. D.R.L.A.V., Paris, n. 26, p. 91-151, 1982.

AUTHIER-REVUZ, J. Hétérogénéité(s) énonciative(s). Langages, Paris, n. 73, p. 98-111, 1984.

1995.

Ces mots qui ne vont pas de soi: boucles réflexives et non-coïncidences du dire. 2 v. Paris: Larousse,

Paradas sobre palavras: a língua em prova na enunciação e na escrita. Educação छ Realidade, Porto

Alegre, v. 36, n. 3, p. 651-679, set./dez. 2011. [Or. Arrêts sur mots: l'épreuve de la langue dans

l'énonciation et l'écriture. In: FENOGLIO, I. (Ed.). L'écriture et le souci de la langue. Paris: Editions du CNRS, 2004.]

Musiques méta-énonciatives: le dire pris à ses mots. Marges Linguistiques, 7, p. 85-99, mai 2004.

BAUMAN, Z. Identidade [entrevista com Zygmunt Bauman, por Benedetto Vecchi]. Rio de Janeiro: Zahar Editores, 2005.

BARTHES, R. Da obra ao texto. In: O rumor da língua. 2. ed. São Paulo: Martins Fontes, 2004 [1971]. p. 65-75.

BENVENISTE, E. Problèmes de linguistique générale I. Paris: Gallimard, 1966. 
BRANCA-ROSOFF, S. Formação discursiva: uma noção excessivamente ambígua? In: BARONAS, R. L.; KOMESU, F. (Org.). Homenagem a Michel Pêcheux: 25 anos de presença na análise do discurso. Campinas (SP): Mercado de Letras, 2008. p. 127-148.

COURTINE, J.-J. Crônica do esquecimento ordinário. In: da fala pública. São Carlos: Claraluz, 2006 [1986]. p. 29-36. Metamorfoses do discurso político: derivas

DELEUZE, G.; GUATTARI, F. Mil platôs - Capitalismo e esquizofrenia, v. 2. São Paulo: Editora 34, 1995.

ECO, U. Kant e o ornitorrinco. Tradução de Ana Thereza B. Vieira. Rio de Janeiro: Record, 1998.

GERALDI, João Wanderley. Linguagem e identidade: breve nota sobre uma relação constitutiva. Ciências $\Xi^{2}$ Letras, Porto Alegre, n. 49, p. 9-19, jan./jun. 2011.

GUILHAUMOU, J. Où va l'analyse du discours? Autour de la notion de formation discursive. Argumentation et Analyse du Discours, n. 9, p. 95-114, mai 2005. Disponível em: <http://www.revuetexto.net/Parutions/Marges/oo_mlo92005.pdf>. Acesso em: 20 jan. 2014.

INDURSKY, F. Formação discursiva: ela ainda merece que lutemos por ela? In: SEMINÁRIO DE ESTUDOS EM ANÁLISE DO DISCURSO - SEAD, 2., 2005. Porto Alegre. Anais... Porto Alegre: UFRGS, 2005.

KRIEG-PLANQUE, A. A noção de “fórmula” em análise do discurso: quadro teórico e metodológico. Trad. Luciana Salazar Salgado e Sírio Possenti. São Paulo: Parábola, 2010.

MAINGUENEAU, D. Unidades tópicas e não-tópicas. In: Cenas da enunciação. Org. Sírio Possenti e Maria Cecília Pérez de Souza-e-Silva. São Paulo: Parábola, 2008 a. p. 11-26.

Michel Pêcheux: três figuras. In: BARONAS, R. L.; KOMESU, F. (Org.). Homenagem a Michel Pêcheux: 25 anos de presença na análise do discurso. Campinas (SP): Mercado de Letras, $2008 \mathrm{~b}$.

Que cherchent les analystes du discours? Argumentation et Analyse du Discours, n. 9, p. 2-14, 2012. Disponível em: <http://aad.revues.org/1354>. Acesso em: 23 jan. 2014.

MALDIDIER, D. L'inquiétude du discours - textes de Michel Pêcheux choisis et présentés par Denise Maldidier. Paris: Editions des Cendres, 1990.

L'inquiétude du discours. Un trajet dans l'histoire de l'analyse du discours : le travail de Michel Pêcheux. Semen, n. 8, 1993. Disponível em : <http://semen.revues.org/4351>. Acesso em: 25 jan. 2014.

NESBØ, J. A casa da dor. São Paulo, Record, 2009. (Coleção Negra).

NEVES, A. Experiências extremas (no sentido de opostas). Crônica. Diário Catarinense, 29 jan. 2014. Caderno Variedades, p. 3.

ORLANDI, E. P. Exterioridade e ideologia. Cadernos de Estudos Linguísticos, n. 30, p. 27-33, jan./jun. 1996. Discurso e texto: formulação e circulação dos sentidos. Campinas : Pontes, 2001.

PÊCHEUX, M. Semântica e discurso: uma crítica à afirmação do óbvio. Campinas: Pontes, [1975] 1988. 49-57. Papel da memória. In: ACHARD, Pierre et al. Papel da memória. Campinas: Pontes, 1999 [1983]. p.

PÊCHEUX, M.; FUCHS, C. A propósito da Análise Automática do Discurso: atualização e perspectivas (1975). In: GADET, F.; HAK, T. Por uma Análise Automática do discurso. Uma introdução à obra de Michel Pêcheux. Campinas: Ed. da Unicamp, 1990 [1975]. p. 163-252. 
PONZIO, A. A revolução bakhtiniana. Coordenador de tradução Valdemir Miotello. São Paulo: Ed. Contexto, 2008

RORTY, R. Pragmatismo: a filosofia da criação e da mudança. Belo Horizonte: Editora UFMG, 2000.

SARNEL, R. Lieux de passages et transversalités: Pour une dynamique deleuzienne. Le Portique, n. 20, p. 18, 2007.

TAMBARA, E. Educação e identidade nacional brasileira. Ciências \& Letras, Porto Alegre, n. 49, p. 21-42, jan./jun. 2011.

Recebido em 02/og/2014. Aprovado em 16/06/15. 